nomson

glyndîn

Glyndŵr University

Glyndŵr University Research Online

Marketing

Business and Management

$1-1-2010$

\title{
Ethnographic Approach to User-Centred Evaluation of Telecentres
}

Bidit Lal Dey

GlyndwrUniversity, b.dey@glyndwr.ac.uk

David R. Newman

Renee Pendergast

Follow this and additional works at: http://epubs.glyndwr.ac.uk/mkt

Part of the Computer Engineering Commons, Entrepreneurial and Small Business Operations

Commons, Signal Processing Commons, and the Technology and Innovation Commons

This paper appears in the International Journal of Innovation in the Digital Economy (IJIDE) authored by Dey, B. L. and Newman, D.R. Copyright 2010, IGI Global, www.igi-global.com. Posted by permission of the publisher. The published article is also available at 10.4018/

jide.2010070102">http://www.igi-global.com>

\section{Recommended Citation}

Dey, B. L. and Newman, D.R. (2010) 'Ethnographic Approach to User-Centred Evaluation of Telecentres '. International Journal of Innovation in the Digital Economy (IJIDE), 1(3), 22-39

This Article is brought to you for free and open access by the Business and Management at Glyndŵr University Research Online. It has been accepted for inclusion in Marketing by an authorized administrator of Glyndŵr University Research Online. For more information, please contact 


\section{INTERNATIONAL JOURNAL OF Innovation in the Digital Economy}

July-September 2010, Vol. 1, No. 3

\section{Table of Contents}

Special Issue: Digital Divide - Part II

\section{Guest Editorial Preface}

$i \quad$ Stephen Mutula, University of Botswana, Botswana

Subhajit Basu, University of Leeds, UK

\section{Research Articles}

1 Next Generation Networks: A New Digital Divide?

Rohan Kariyawasam, Cardiff University, UK

22 Ethnographic Approach to User-Centred Evaluation of Telecentres

Bidit Lal Dey, Queen's University Belfast, UK

D. R. Newman, Queen's University Belfast, UK

Renee Prendergast, Queen's University Belfast, UK

40 For All of Our Languages We are Not Natives Here: Challenging the Idea of the Digital Native, Rethinking the Digital Divide

Martina Gillen, Oxford Brookes University, UK

56 Deconstructing the 'Digital Divide' In Africa

Stephen Mutula, University of Botswana, Botswana, and University of Zululand, South Africa 


\title{
Ethnographic Approach to User-Centred Evaluation of Telecentres
}

\author{
Bidit Lal Dey, Queen's University Belfast, $U K$ \\ D. R. Newman, Queen's University Belfast, UK \\ Renee Prendergast, Queen's University Belfast, UK
}

\begin{abstract}
Telecentres are considered to be an important means for providing disadvantaged communities with access to Information and Communication Technology (ICT) enabled services. However, there is a limited understanding of how targeted beneficiaries perceive the roles of these telecentres. Using an ethnographic approach, this paper examines the services offered by two telecentres in Bangladesh. An intervention was initiated that enabled groups of farmers to use mobile 'phones to access services. Based on farmers' experiences and opinions the authors develop a framework which explicates the dynamic nature of use and appropriation of ICT services.
\end{abstract}

Keywords: $\quad$ Appropriate Technology, Community Information Centre, Farmers, Grameenphone, Mobile Telecommunications, Pallytathya Kendra, Technology Acceptance

\section{INTRODUCTION}

This paper argues that a bottom-up approach to the introduction of Information and Communication Technology (ICT) enabled projects and to the appropriation of different ICT tools in accordance with the needs and cultures of rural populace are major prerequisites for those projects to become effective. The paper outlines an approach to the evaluation of telecentre projects which focuses on understanding about how and why the intended beneficiaries make use of, and benefit from, the information and

DOI: 10.4018/jaeis.2010070102 communications made accessible through the centres. If ICT is to have an impact on development, it needs to be assessed from the perspectives of beneficiaries, as opposed to the routine monitoring of operations carried out for NGOs and funders.

An ethnographic approach was adopted in designing and implementing a method of evaluating the services of two telecentre projects in Bangladesh. The research was set out to understand the crucial information needs of rural Bangladeshi farmers and how current and potential interaction between telecentres and farmers could assist in meeting those needs. The principal needs identified related to a lack 
of market information and bargaining power, a lack of scientific knowledge and a lack of information about weather.

This research focused on the role of two telecentres: D-Net ${ }^{1}$ 's Community-based Technology Centre (CTC) and Grameenphone and Katalyst ${ }^{2}$ 's GPCIC(Grameenphone Community Information Centre). D-Net, a Bangladeshi NGO runs the Microsoft Unlimited Potential Project for their Pallytathya Kendra (a type of CTC). This project was developed to improve access to the livelihood-relevant information for the rural people. On the other hand, Grameenphone is the largest mobile phone operator of the country. Though Grameenphone (widely known as GP) is a profit seeking concern, it is partly owned by the Grameen Bank (a microfinance providing NGO, headed by Nobel laureate Dr. Yunus).

\section{RELEVANT LITERATURE}

There is considerable doubt about the success of top down approach to implementing ICT enabled projects in developing counties (Kirlidog \& Aydemir, 2005; Leaning, 2005; Nikam, Ganesh, \& Tamizhchelevan, 2004). Local contexts need to be taken into consideration while developing contents and applications. In order to conduct meaningful assessments, it is necessary to know whether or not ICT interventions address the local needs. To show the necessity for this approach and to provide the required background and context, this section provides a brief overview of the agricultural structure in rural Bangladesh and outlines the potential contribution of improved knowledge and information to its development. The contribution of ICTs including telecentres to resolving information problems as outlined in the existing research is then examined. The final part of the section provides a critical examination of the main theoretical models used for the analysis of technology acceptance in the information systems literature. While recognizing the conceptual strengths of these models, it argues for their supplementation by models taken from the social science literature in order to capture fully the dynamic interactions between society and technology.

\subsection{Farmers in Rural Bangladesh}

In a country like Bangladesh farms are extremely small, cultivation is dependent on the uncertainties of variable rainfall and average output is generally low. Value addition in agriculture requires technological, institutional and price incentive changes designed to raise the productivity of the small farms (Todaro, 2000). In addition to activities designed to raise the productivity of agriculture, rural development requires the creation of opportunities outside the agricultural sector which are currently extremely limited.

In 1991 the top ten percent of landowners owned sixty percent of the land, while the bottom sixty percent of landowners had only one percent of the land (Ullah \& Routray, 2007). This ownership structure is considered to be a major impediment to balanced rural development (Rogaly, Harriss-White, \& Bose, 1999). Small farmers are entangled within a vicious cycle because of sharecropping, tenancy, money lending and other structural and financial relationships with owners and traders (Crow, 1999). The situation of the vulnerable farmers is exacerbated by land erosion, drought, flood, deforestation and other natural calamities. This together with lack of financial power reduces farmers' propensity to take risks. Lack of bargaining power raises input prices and reduces net earning which in turn impacts negatively on farmers' productivity.

Imperfect information and high transaction costs can constitute major impediments in the agricultural marketing process (Dao, 2004). Proper dissemination of information for agricultural and rural communities has the potential to allow farmers to improve revenues while reducing the associated transaction costs and production costs. Information generally helps the poor to avail of the opportunities 
and also reduce their vulnerability (Kizilaslan, 2006). It can also facilitate effective adoption of agricultural inputs, decision making on markets and adoption of scientific methods (Kiplang'at, 1999). However, lack of dissemination of information across the agricultural supply chain is a major concern in the developing world especially in rural parts of poor countries such as Bangladesh. Its potential impact on the bargaining power and productivity of Bangladeshi farmers is depicted in Figure 1.

\subsection{The Role of ICTs in the Resolution of Farmers' Problems}

Research conducted by Lio and Liu (2006) has found strong correlation between the use of ICT and farmers' productivity. Lio and Liu (2006) have also suggested that use of ICTs could increase the bargaining power of farmers. Moreover, with the access to information, small scale farmers could improve their competitiveness over the larger operators. Improvements in knowledge and information allow farmers to make better crop choices, develop products for the niche markets and even market the products directly to consumers. Rural telephone and community radio services initiated in India and Sri Lanka engendered remarkable response from farmer communities (Lio \& Liu, 2006). Bayes (1999) has identified that the Village Phone Program (VPP) of Grameen Bank of Bangladesh can convert the telephones into production goods by lowering transaction costs.

Despite these positive results, concern has been expressed as the impact of ICT enabled projects is not maximized. Mutula (2005) believes that resources utilized to bridge the digital divide would have more impacts if they were directed to meet the basic needs of the poor. However, he has been optimistic about the outcome of the effective use of ICTs. Heeks (1999) considers that ICT can contribute positively to development if it is used appropriately. Donner (2008) argues that assessing the projects and their impacts has been and remains a major challenge in the ICT for development research.

\subsection{Telecentres' Role and Their Evaluation}

Community based use of the ICTs is regarded as a means of widening and cheapening access to them in developing countries. Telecentres are a means to provide public access to long distance communication and information services through the use of wide range of information and communication technologies (i.e., fax, telephone, computer and Internet) (Whyte, 2000). A telecentre can be a phone shop, or a cybercafé. However, some telecentres, known as multipurpose community telecentre (MCT) are designed to provide a bundle of services such as medical and livelihood solutions. Telecentres can be run by private or public entities. They can also be run by not for profit organizations, funded by international donor agencies.

The evaluation of telecentres is a major concern for researchers and practitioners. Different approaches to monitoring and evaluating have been tried and advocated. By and large they have concentrated on two major aspects:

- The operations of a telecentre: How a telecentre operates, how efficient its operations are, what type of information it disseminates and which groups it benefits, how the operation takes account of social and cultural factors and so forth.

- The impacts of telecentres: What are the economic impacts, what are the social and political impacts? In other words, what are the quantitative and qualitative impacts

Recently, telecentre sustainability has emerged as a major issue for research. While, much of the focus has been on financial/economic sustainability, the importance of social sustainability has been emphasized by a number of authors including Bailur (2007) and Bailey (2009). A key aspect of social sustainability is the extent to which telecentres respond to and meet community information needs and contribute to overall community development (White, 2000; Harris, 2001). In evaluating the 
Figure 1. Reasons behind lack of bargaining power and lack of productivity of the farmers of Bangladesh. Source: Adapted from literature review

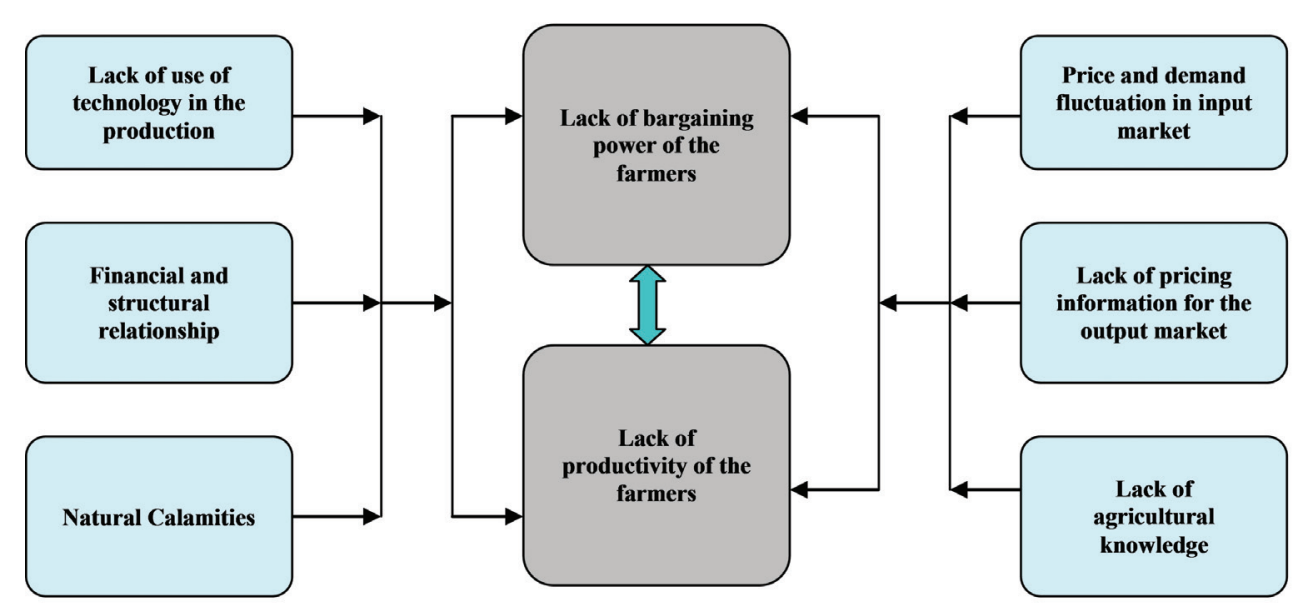

extent to which telecentres meet the needs of the community, it is important to begin by identifying these needs. These should be as defined by community members themselves and not as identified either by providers or researchers. As Bailur (2007) points out, the failure of many studies to adequately identify the stakeholders and their needs casts doubt on their findings with regard to the contribution of telecentre's to economic and social development. An extensive review of research on public access to ICTs by Sey (2008) has concluded that no clear link could be found between telecentres and their economic and social impacts. The social and contextual use and the resulting impacts clearly remain as important issues for research.

Users' behaviour needs to be considered as a part of their culture and social structure. It is also important to identify and comprehend the methods used for exchanging information in a given social structure and how that can be facilitated and/or inhibited by the services of telecentres.

\subsection{Acceptance and Appropriation of ICTS}

The acceptance of information technology has been widely used and discussed in IS (Informa- tion Systems) research. The theoretical frameworks most commonly used in the investigation of this issue are the Technology Acceptance Model (TAM), the Theory of Reasoned Action and the Theory of Planned Behaviour. TAM, one of the most robust models, is focus of our attention here.

The Technology Acceptance Model pioneered by Davis (1989) examines the mediating role of perceived ease of use and perceived usefulness in relation to the attitude towards a particular technology or IS application. Firstly people tend to use an application if it enables them to perform their job better. This is referred as perceived usefulness. However, even if users believe that an application is useful, they may not find it easy to use. The benefits can be outweighed by the effort of using an application. Perceived ease of use is users' perception about how easily a particular application can be used. A later version of this model TAM 2 (Venkatesh \& Davis, 2000) identifies perceived ease of use as a determinant of perceived usefulness. In a further development Venkatesh and Bala (2008) propose a TAM 3 model which adds image, output quality, job relevance and result demonstrability as the determinants for perceived usefulness and computer selfefficacy, perception of external control, computer anxi- 
ety, computer playfulness perceived enjoyment and objective usability as the determinants for perceived ease of use. A weakness of TAM models is that none of them reflects the dynamic nature of technology appropriation. Despite this limitation, perceived usefulness and perceived ease of use are valuable constructs for the investigation of technology acceptance.

Technology not only facilitates human actors, it also constraints their activities. This paradox cannot be captured within the TAM model (Baron, Patterson, \& Harris, 2006). Snowden, Spafford, Michaelides, and Hopkins (2006) have used an action research approach to assess the technology acceptance for m-commerce. They argue that it is equally important to find how practitioners can intervene to positively affect the acceptance and therefore the adoption of new technologies. This is particularly necessary when the potential users are not very aware of the technological applications.

ICTs are designed to cater the needs of a broader community. In most cases a technology developed in a western country reflects the lifestyle and culture of that country. While society and technology shape each other, technology developed in the context of one socio economic setting can be appropriated for use in another. How individuals are likely to use technologies and with what (intended or unintended) consequences in different conditions (Wiredu, 2007) depends on a number of factors including its compatibility with existing lifestyles and social structures.

In structuration theory as developed by Giddens (1982), the social structure is seen as the result of recursive interaction among human agents, institutionalized rules and material resources. As such the concept of structuration provides a useful framework for the investigation of interactions between technology, life style and social structures. Stillman and Stoecker (2005) have used structuration theory to identify and diagnose the sustainability issues for a community organization. Orlikowski's (1992) work has used structuration theory to analyze users' adoption of IS application in organizational settings. Although the approach has become popular in the qualitative research on IS adoption little work has been done to use this theory to complement the shortcomings of technology acceptance model. This paper however, uses this theory to assist in the development of an understanding of the social and cultural aspects that limit or facilitate farmers' interaction with telecentres. Giddens' (1982) concept of the duality of structure explains that structural properties of social systems are both the medium and the outcome of the practices that constitute those systems. Here the concept is used to develop an understanding about how human agency (rural farmers) through interaction with material resources (ICT applications) and institutionalized rules (the rural lifestyle in Bangladesh) can confront or overcome the problems pertaining to the existing agricultural system.

\subsection{Summary of Literature Review}

As it is evident from the literature discussed above, if telecentres are to make a positive contribution to a context such as that of the agriculture of rural Bangladesh, a number of conditions have to be fulfilled. These are that the services of telecentres have to satisfy farmers' information needs (to ensure the perceived usefulness), that their services are easily accessible for farmers (to ensure perceived ease of use) and that they are consistent with rural lifestyle (to facilitate the appropriation of services). Any evaluation targeted to explore the effectiveness of telecentres' roles should investigate how and to what extent these objectives can be achieved.

\section{RESEARCH DESIGN}

\subsection{Overall Objectives}

Based on conceptual framework the research objectives are listed:

1. Identifying farmers' agricultural information needs. 
2. Enumerating the telecentre services farmers choose to use to meet their agricultural information needs and how they do so.

3. Understanding how farmers appropriate those services and integrate them in their daily lives.

We decided to conduct ethnographic fieldwork that would enable farmers to get connected with telecentres. The objectives of this research require a close observation of the rural life and culture in Bangladesh. By staying close to the farmers in their own social and cultural setting we had the opportunity to comprehend why and why not they make use of telecentres and how they attempt to integrate their services in their lives. We also wanted to have a clearer understanding about the subtle attributes in the physical and social environment that influence on farmers' agricultural information needs and their interaction with telecentres.

Ethnography has engendered interest in the field of information systems and consumer research. Venkatesh, Stozoff, Shih, and Majumdar (2001) have used ethnographic research to conceptualize the development of innovative use of technology in the home environment. By visiting the residences of different consumers they have come in terms with the nature of interaction and physical layout within the home environment. This understanding is used in developing their theory about interaction between technology space and physical/environmental space. O'Brien, Rodden, Rouncefield, and Hughes (1999) have presented an example of "speedy ethnography" to find the domestic use of information technologies. They have chosen to engage with the informants for shorter period, as longer stay could have caused inconvenience to the subjects. Informal interviews and observations during brief stays in the households have enabled them to eschew such difficulties. Through ethnographic evaluation they obtained an understanding about the nature of home life and how that implicates the use of digital services.
While duration of engagement is inhibited by informants' inconveniences (Elliott \& Jankel-Elliott, 2003), researchers' objectives and time famine can also limit the scopes of using ethnographic methods. In order to obtain quick feedback from the field Millen (2000) proposes a condensed version of using ethnographic method, which he has named "rapid ethnography". The process requires researchers to develop a narrow focus of the topic and participants in the beginning to make best use of the time in obtaining relevant and useful findings. Condensed and quick ethnographic immersion has also been used to find the immediate adoption of mobile devices (Weillanmann, 2001). Hence we understand -

- Shorter period of engagement can still generate useful findings.

- Shorter period of engagement can be particularly useful to minimize subjects' inconvenience and find their immediate reaction about a technological intervention.

- Before embarking on the fieldwork, researchers need to set-up major area of investigation to avoid unnecessary delay and irrelevant findings.

In this research the duration of fieldwork was for four months. The duration was decided for two major reasons - first we intended to extract early adoption and appropriation of telecentres by farmers. Second, January to April constitute an agricultural season in rural Bangladesh. Engaging during this period of time would enable us to find the different patterns of use at different stages of cultivation. The duration was long enough for comprehending farmers' response to telecentres' services. The researcher (first author) did not stay with one particular group throughout the period. Rather the researcher went back every alternate week and spent time with them. Hence, informal discussions and observations were useful tools for this research. Clearly articulated research objectives and plans also expedited the data collection process. 


\subsection{Context}

D-Net partnered with Gandhi Ashram, a local NGO to set up the Pallytathya Kendra (rural information centre) at Joyag, Noakhali, as a part of the Microsoft Unlimited Potential Project. The location is situated at the South East corner of Bangladesh, around 120 miles from the capital city of Dhaka. While the salaries of the employees are paid by D-Net, Gandhi Ashram provides the infrastructure and logistic support. According to the Gandhi Ashram authority 90\% of the project cost is covered by them, and DNet pays for the rest.

Grameenphone Community Information Centre (GPCIC) is a joint project initiated by Grameenphone, Katalyst (funded by a donor consortium comprising of SDC, DFID and SIDA) and Grameen Telecom. GPCICs are set up in different corners of the country with an aim to providing Internet connectivity and other ICT facilities in rural areas. Unlike, the Pallytathya Kendra, GPCIC is an entrepreneurial project. It is expected that the young entrepreneurs of rural Bangladesh can develop profitable ventures by selling ICT services (i.e., electronic top up of mobile 'phones' credits, photocopying and Internet access). Grameenphone provides the GSM/GPRS/EDGE infrastructure and other partnering organizations provide training and content support for the entrepreneurs. A typical GPCIC hosts a number of ICT tools including computers with Internet connectivity through EDGE technology, telephone, photocopier and printer. There are more than 400 GPCICs across the country. We chose the one based in Shaturia Upazila (sub-district) of Manikganj district 40 miles from the capital city of Dhaka. Table 1 presents features of GPCIC at Shaturia and Pallytathya Kendra at Joyag:

The first author of the paper travelled to Bangladesh to conduct the fieldwork. He worked with both of the projects (GPCIC and Pallytathya Kendra) to implement a planned intervention. The following points were taken into consideration while designing the fieldwork project:
1. We had to implement an intervention to facilitate the farmers' access to the CTC (Pallytathya Kendra) and GPCIC.

2. Acommunity based access was necessary to see how farmers develop network amongst themselves and how they share information and technology.

3. We had to provide all the farmers in the intervention group with the equal opportunity to get access to the CTC and GPCIC.

\subsection{Fieldwork}

The initial planning and preparation started from 1st week of January, 2008. The first one month was spent mingling with the farmers and learning about their problems. In-depth interviews and focus group discussions (FGD) were complemented by first author's own observation to comprehend farmers' life style, their means for communication, and their problems with respect to different economic and social issues. Farmers' opinions regarding the use and availability of fertilizers, use of technology in farming and non farming activities were gathered. Their perception about the telecentres was also investigated during this period.

Small farmers' groups were formed. Each group had five members. The groups were formed on the basis of geographic, religious and family connectivity so that the farmers in a particular group could comfortably get along with their fellow group members. Each of the groups was given a mobile telephone with connection. Each of the members of the group had the opportunity to keep the phone for two weeks. This was done to connect them with telecentres. We wanted to notice whether or not they contacted the centre for agricultural information. The intervention continued for 10 weeks until the end of April. The first author met the groups once in every two weeks. These groups had the opportunity to contact the telecentres as well. Through the use of the mobile telephony the intervention provided the farmers with an opportunity to communicate the centres without visiting them. The first author visited the farmers 
Table 1. The features of GPCIC and Pallytathya Kendra

\begin{tabular}{|l|l|l|}
\hline & GPCIC at Shaturia & Pallytathya Kendra at Joyag \\
\hline Nature of the location & Located at a semi-urban area & Located at remote rural area \\
\hline Source (s) of finance & Entrepreneur's own investment & Gandhi Ashram Trust and Microsoft \\
\hline Technical expertise and support & Grameenphone & $\begin{array}{l}\text { The trained staff of Pallytathya } \\
\text { Kendra does the trouble shooting. }\end{array}$ \\
\hline Service Offerings & $\begin{array}{l}\text { E-mail, web based fax, online chatting, } \\
\text { photocopying, electronic top up facili- } \\
\text { ties for mobile phones and computer } \\
\text { training. }\end{array}$ & $\begin{array}{l}\text { Computer training and Pallytathya } \\
\text { solutions for public health related } \\
\text { issues and non farming businesses } \\
\text { for rural women). }\end{array}$ \\
\hline $\begin{array}{l}\text { Duration of operations (till January } \\
\text { 2008) }\end{array}$ & One year & Less than one year (seven months) \\
\hline
\end{tabular}

and stayed with them for two to three days in every two weeks. The farmers were supported by the representatives of Gandhi Ashram, and GPCIC when the first author was not around.

Weekly meetings within each group were regularly monitored to find out different aspects of the use of mobile phones and telecentres by the farmers. FGDs with farmers' groups and interviews with the individual farmers were conducted. The following issues were examined in the meetings:

- How did they manage to contact the centres?

- How helpful were the centres?

- What did they perceive about the operations of the telecentres?

- What were the benefits they received?

- Whether the mobile telephony technology and the telecentres had been helping them to overcome the obstacles to get information (mentioned during the initial FGD) or not? If so, then how? If no, why?

The first author conducted FGD and indepth interviews with the group members. The outcome from the discussion with one group was checked with that of the other groups. The first author also interviewed the other members of farmers' families, who made more use of the mobile 'phones. This was done to find what made them to make use of the mobile 'phones.
He took diary notes describing daily lifestyle, practices and culture. The first author visited crop fields to capture the photographs of pests. He videoed the rural environment to find some interesting objects - lack of space in farmers' houses to keep cattle, shops at the remote villages who top up mobile phones, the rural muddy roads and so forth. He also observed different aspects of farmers' daily activities including how farmers work with the irrigation, how they top up the mobile phones, how they mingle amongst themselves.

The intervention was over by the end of April. The next stage involved transcription of data, from audio and video tapes and field notes, using Transana ${ }^{3}$, computer aided qualitative data analysis software that is designed to work with video and audio recordings. The diary notes collected from the field were used to assist the interpretation of the data collected from the FGDs and interviews. Transcribed texts were coded mainly based on the existing theories. The detail of the coding system is not explained here, as this paper is built on the initial findings and observation.

\section{FINDINGS}

This section gives examples of some of the findings that came out of this research approach. It is not intended to be a comprehensive evaluation of the two telecentres though. The first stage of 
Figure 2. Telecentres'operations and social structure

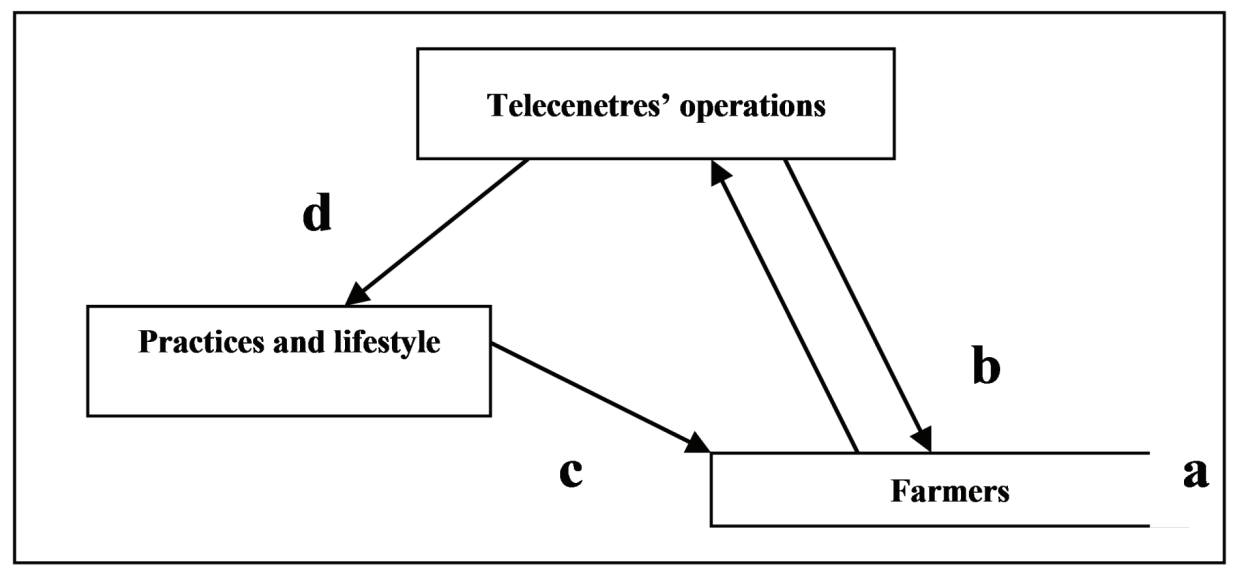

the action research involved needs assessment. Hence, we explored the agricultural information needs of the farmers. We found that sources and prices of fertilizers and solution of pest attacks and plant diseases were major information needs. We were particularly interested to know whether or not the telecentres were useful for farmers to get output price information, as there is a widely held belief that ICTs can be used in exchanging price information of agricultural produce. Based on the needs assessment and farmers' opinions about the output price information we developed an understanding about the perceived usefulness and perceived ease of use.

\subsection{Needs Assessment:}

Our research set out to investigate farmers' information needs. The following issues have been identified:

\section{Prices and Sources of Fertilizers:}

In Bangladesh fertilizer costs are subsidized and the government fixes the price range to prevent price manipulation by dealers. Although local government members and administrators are responsible for monitoring the distribution of fertilizers, we found that the price and avail- ability of fertilizers are still major concerns for farmers. As one of the farmers tried to explain the situation:

I need to put twelve $\mathrm{kg}$ fertilizers in my land. We used to use the organic fertilizers in the past days and $5 \mathrm{~kg}$ chemical fertilizers were enough. ${ }^{4}$

One farmer told about the prices and availability of fertilizers:

No, we do not get it (fertilizer). Even if we get, the price is too high. There is a particular variant of fertilizer, known as red fertilizer, happened to cost us TK5 12 last year. Now the price of the same fertilizer is TK28-TK30. Now you can imagine how difficult it is for us.

Farmers believed the local government members and dealers also created artificial crises, and that nepotism and corruption worsened them.

\section{Information About the Pests, Crop Diseases and Cultivation Methods}

The farmers of Joyag and Shaturia came across increasing problems with the pests and plant diseases. They are not very familiar with many 
of these pests and the plant diseases. They told that the following reasons are causing these problems:

Weather conditions: In Bangladesh the nature has been behaving in an uncharacteristic manner for the last few years. The agricultural system in Bangladesh is very much dependent on the weather and seasons. Any change in the climate or seasonal weather can stimulate plant diseases and pest attacks. When the fieldwork was conducted, the winter started much later than the usual case. Normally the winter starts from middle of December. That year (2007-08) the winter did not arrive till middle of January. Throughout the month of February it was overcast and quite cold. February is the beginning of the Bengali spring though. The farmers said that this unseasonal weather caused strange plant diseases which they were not familiar with. There were also some strange pests in the field.

This year we are unable to understand the nature's characters. We are not having any spring this year.

We come across new pests. The pests have destroyed the potato field. Even in the corn field there are some strange pests.

Cultivation of hybrid crops and the use of chemicalfertilizers: The elderly farmers told that pest attack and plant diseases had increased since they started cultivating hybrid crops and using chemical fertilizers.

Inadequate agricultural extension workers: As most of the farmers are semi-literate or illiterate they do not have any academic knowledge about farming and cultivation. There are employees of the Ministry of Agriculture of the Government of Bangladesh to help farmers in resolving these problems. These people are known as block supervisors. There are two block supervisors in each Union Parishad (a unit of local government). Joyag is a Union, while Shaturia is a Upazila - sub-district (comprises of nine unions). A typical union consists of fifteen villages. Two block supervisors are inadequate to support farmers of such a vast area. Hence, contacting these block supervisors is a major concern for the farmers.

\subsection{Output Price Information}

The structural and financial relationships in the agricultural production system (between farmers and landlords, between farmers and brokers and farmers and money lenders) are major impediments for farmers' empowerment and welfare. Farmers often take loans from the solvent people in their area. These people are often their landlords and brokers (who work for the bigger wholesalers) for the yields. These people are also their customers, as they often sell a part of their produce to their landlords. Again, farmers need to borrow money from these individuals for different reasons. At different stages of the cultivation they require hard cash to buy fertilizers, pesticides, to pay off diesel and electricity bills. Particularly by the end of the season they need financial support to pay off all the debts, incurred during different phases of the cultivation. They also need to pay the day labourers that help them during the harvest season. When they are in dire need of the hard cash they borrow money from the landlords or the brokers.

They pay (the brokers) us less; often they cheat on us while measuring the crops. Basically at the end of the cultivation season we need hard cash. We need to pay debts; we need to pay labours. This is why we do not wait for anything. Say even if the normal price of one maund ${ }^{6}$ of rice is TK500, we often end up getting TK400 per maund due to such pressure.

If farmers had not taken any loan from any of their customers, they could have been in a position to sell their produce at the market 
price. It is often argued that through the use of ICTs farmers can learn about the wholesale price and thereby can achieve superior position in terms of bargaining power. This may be true for fishermen (who remain mobile with their produce), but may not be the case for the Bangladeshi paddy producers, particularly the sharecroppers. The following reasons can be identified -

The traditional trading system: Traditionally the brokers of the big wholesalers or millers (who convert the paddy to rice) visit the village farmers. They move from door to door to buy the produce. As a result often farmers do not have any chance to verify the price at the local market. They normally discuss among themselves to find right price of the produce though.

Risk of keeping the paddy/rice for longer time: Farmers are often concerned about keeping the paddy/rice for longer period at their disposal. Rain water, rats and insects may damage their hard earned harvest. Hence they prefer to sell off the produce as soon as they can.

Risk of taking the produce to the bazaar: Farmers often cannot afford the cost of taking the produce to the nearest bazaar. The financial risk is quite high as well. This is why they prefer to sell the produce at their door steps.

\subsection{Farmers' Perceptions and Behavioural Intentions}

Both of the centres were within the first year of their operations when the project was initiated. This was not long enough to make a substantial impact on the lives of many local residents. Farmers, the target users, were yet to embody the use of telecentre services in their daily lives and farming practices. However, it is important that farmers find these centres helpful in resolving their problems. Based on the theories pertaining to the study of technology acceptance we can analyze the two major determinants of behavioural intention in this regard. We also find how social structure and lifestyle influence on farmers' perceptions.

\section{Perceived Usefulness}

Farmers need to have the belief (an organized pattern of knowledge) that the centres can satisfy their information needs. In other words, farmers need to believe that the centre is going to be useful for them. It has been observed that the training programmes of the centre are preferred by local young population. They consider these training courses will be extremely helpful for them to secure overseas employment opportunities. As a result local teenagers and young adults (many of their fathers are into farming activities) assemble at the centre. One of the trainees told the first author:

I came to the centre to learn computer. I believe this learning would be helpful for me in future. I pay TK1200 for the entire course, which is reasonably expensive. But this is worth it.

The farmers, on the other hand, are not convinced that the centres can be of any use for them. This is why they do not visit the centres. As one of them said:

\section{What can I do with the computer?}

There seems to be a gap between the information needs of the farmers (as explained above), and what the telecentres provide.

\section{Perceived Ease of Use}

The services farmers receive from the centres need to be easily used. Making something available is not the same as making it usable. The "Jion" package or ruralinfobd.com, answers many of the basic agriculture related questions. However, many farmers do not know how to operate a laptop or how to access the Internet. As Talbot and Newman (1998) explained in the context of community groups' learning to use the Internet in Northern Ireland, there are hurdles people have to overcome before they can make 
effective use of such tools, what they called the "how-to" gap (or effective use). To learn how to use these tools and ruralinfobd.com, they need not only to learn a set of computer literacy skills, but they also need to learn the potential benefits. Otherwise they will not be motivated to visit the centre often enough. Farmers even do not know what computers can do for them. As they registered during the interviews:

No I have not used the computer at the Gandhi Ashram, because when we are free the office is closed. And we do not have time to go to the Gandhi Ashram and explore the computer.

No I do not have any clue about what they (computers at Gandhi Ashram) are for.

However, some farmers were interested in trying to use electronic communications to help identify pests infecting their crops, as an alternative to trying to get hold of a block supervisor. In Shaturia photographs were taken, and sent over MMS and the Internet to people who might help identify the pests. The local telecentre staff did not have the expertise to identify the pests, nor were the block supervisors able to receive and respond to electronic images. It took two weeks to get a reply from the concerned persons of Katalyst, based in Dhaka. They had to find a specialist to identify the pests. By that time the entire potato field was destroyed. The delay in getting response made the farmers skeptical about the effectiveness and efficiency of the process. Talbot and Newman (1998) explained how it is important to experiment with ways of integrating Internet technologies into people's lives. But not everyone is willing to spend much time experimenting, if they perceive the technology as either difficult to use or useless.

Any software package or service to cater the needs of the farmers has to be developed with a bottom up approach, starting from the needs of the farmers. It is expected that GPCIC can disseminate agricultural information from the website www.ruralinfobd.com. During the fieldwork project the website was still under construction, so this could not be tested. Furthermore, some needs will be better met by instant communication (e.g., pest identification, local prices for inputs and outputs), rather than static information.

\section{SOCIAL STRUCTURE AND SOCIAL CHANGE}

Farmers have their own way to accomplish their tasks. They have been following certain traditions and practices for years. Farmers have their own way to collect information about fertilizers, pesticides and appropriate prices of their produces. Farmers tend to move from one bazaar to another to learn about the prices and sources of fertilizers. We observed that farmers easily accepted the use of the mobile telephony to find fertilizer prices. This was possible, because the traditional process could easily accommodate the use of the technology. Farmers were still contacting the same people (other farmers or the dealers) about the same issue (prices and sources of fertilizers). Without changing the human agents (farmers and the people they contacted for information) and the nature of communication, a cheaper and easier mechanism could be developed with the help of the technology. As one of the farmers said:

Yes now I understand. If I go to three different shops it costs me the whole day and can cost me TK 50 for the rickshaw fair. Now I can save this time and TK50 by making three phone calls costing me maximum TK 9.

Here we can see that social structure and the use of technology are facilitating each other. The use of the technology gets embodied within the social practice and generates an important and new dimension of its use. This can be attributed as a typical example of the appropriation of the mobile telephony within the social structure of the rural Bangladeshi life.

However, not all the traditions and practices support simple technological substitution. We noticed that normally at first farmers try to 
solve a problem of their crops (pest attack or disease) with the help of their own experience and knowledge. If they fail to get any solution they get in touch with their neighbours and other farmers. Getting help from the block supervisors or government officials is not very easy. As some of the farmers argued:

We do not think so. Getting access to the block supervisors is not a concern; it is the people that matter. These people will keep us dodging. We do not think the mobile phone (as a means to communicate with the block supervisors) can make any difference in this regard. You even will not get the block supervisors in the office. The agricultural officers and block supervisors take ages to test the soil and give the report. You cannot expect anything from these people.

My main problem is the plant disease that has attacked the eggplant field. The leaves are getting dry. Gradually the leaves are withering. I went to see the block supervisor who could not offer me any solution.

It is not easy to get hold of them (the block supervisors) first point. We actually try to find the solution by consulting the fellow farmers first before we resort to block supervisor or any other expert persons. We share our experience and thereby try to get the solution.

As a result even today farmers try different measures to overcome crop diseases or pest attacks until they get the success. In most cases these measures are either learnt from their experiences or suggested by their fellow friends/neighbours. Now, the use of the software package like "Jion" or getting photograph of the plant/pest and sending it to the nearest telecentre may require a total change of the traditional process. This is why the intervention was not very successful in this regard. A technology needs to be embodied in a set of social institutions to make it work. So, e.g., the use of chipboard requires training courses for carpenters and demonstration factories, otherwise carpenters will use nails or screws, and split the panels. A technology adaptation enables users to get new information through new communication patterns. If the new communication pattern is not preferred by the end users they will not be interested to adapt to the technology (Figure 2).

a-Farmers' intention to adoption to telecentre services

b - Technology facilitating farmers

c-Lifestyle and practices influencing farmers to get benefits from the technology

$\mathrm{d}$ - Telecentre changing the practices and lifestyle

The traditional practices and lifestyle influence the interaction between farmers and telecentres'(c) and its impact. Because farmers are tied in the vicious cycle of money lending and sharecropping, there is less chance that the operations of the telecentres can help them to have much of bargaining power to set the farmgate price for their produces. Farmers who live adjacent to the village bazaars are always in touch with the market prices. Hence, their lifestyle and practices do not get much of value addition through the use of telecentres, as far as getting market price information (for output) is concerned. During the intervention farmers started to collect fertilizer price information or solution for pest attack by using mobile phone and/or asking the telecentre contact persons. Thereby the operations of the telecentres made a change in the overall practices and lifestyes (d). The factors determining farmers' behavioural intention, discussed earlier, explain $a$ and $b$.

\section{ANALYSIS AND CONCLUSION}

We can divide the entire evaluation project into a number of sequential stages:

Stage-1: Understanding the social structure and lifestyle, and assessing needs (analyzing the readiness) 
The services of telecentres and their interaction with farmers are just a small part of their social structure and lifestyle. Telecentres facilitate communications and information retrieval not as an end in itself, but are intended to support rural life. Consequently, the services of telecentres need to be consistent with rural social structure and practices. Social structure and lifestyle can determine how successful an adoption to a technological application can be.

Social structure and lifestyle also determine needs, including information needs. For example, the use of tractors in Bangladeshi villages has increased the demand of chemical fertilizers (as the farmers do not need to keep cattle for ploughing their lands) and thereby has created needs for fertilizer prices and availability information. Needs may also be created because of other reasons like climatic conditions.

As we consider the information needs revealed by this research:

1. One of the reasons behind farmers' lack of agricultural knowledge is the lack of expert support from extension workers. The number of government employed block supervisors is not adequate to support the large farmer community. As a result farmers are unable to tackle vital problems like pest attacks and plant diseases.

2. Lack of inputs including fertilizers is regarded as a major problem for Bangladeshi farmers. They suggest that the nepotism and corruption by the members of local government and dealers have worsened the fertilizer crisis.

3. The findings of this research also reveal why farmers do not have much bargaining power when selling outputs. The existing structure of the agricultural trading system ties farmers to purchasers (e.g. through sharecropping and loan conditions)

Our intervention made an attempt to find how and to what extent these problems encountered by rural Bangladesh farmers can be addressed by using information and communication services.

\section{Stage-2 Understanding the factors determining farmers'behavioural intention (Analyzing the adoption)}

In this regard farmers' perceived usefulness and ease of use are assessed with regard to their behavioural intention to use the services of telecentres. Not all services championed as useful by urban NGOs and donor agencies are used by farmers. They consider either these services are not very useful or they are too inconvenient for them to access. However, their perceptions about these services can be changed or reinforced through their interaction with the centres. The more they would use they would have better understanding about the problems and prospects.

\section{Stage-3 How the interaction can facilitate the social change (analyzing the impact):}

This phase tries to find out how the interaction between farmers and telecentres make and/or initiate change (if they can at all) in the social practices. This research has found evidence that subtle changes in the social communication process (i.e., getting information about fertilizer price) have been initiated by the operations of telecentres. However, it is important to be realistic about the impacts and benefits. The popular notion about telecetnres' utility in disseminating output price information needs to be reconsidered for the sharecropper paddy growers in Bangladesh.

It may require quite a long time to experience any change in social structure, precipitated by ICT enabled intervention. If there is any change in the lifestyle, there can be further problem resulting to some additional needs. For example if farmers get used to enquiring about market price information through mobile telephony, quick and remote top up of the mobile credit will become a crucial need for the agricultural marketing. Hence this evaluation model accepts the dynamic nature of social change and its relation with ICTs. 
The following diagram (Figure 3) relates our findings to theories. Telecentres will be perceived useful, if they can meet farmers' information needs. Services offered by telecentres should be aimed at meeting local needs. Telecentres also need to be easily accessible. In our fieldwork we found farmers are reluctant to visit the centre during day time, when they are busy in the field. They also lack the expertise of using different applications. Farmers'perceived ease of use can be ensured by making telecentres' services easy and accessible. Finally telecentres' services have to be compatible with the local lifestyle and culture. Farmers' interaction with technology takes place within a bigger social context that involves other human agents (i.e., block supervisors, NGO activists, fertilizer traders and other farmers whom farmers communicate with the technology) and systems (i.e., rural lifestyles, agricultural marketing processes, social and business relationships and so forth). A technological application has to be consistent with the systems that limit and/or facilitate its use by the human agents. Through their recursive interaction technological applications, human agents and systems farmers can embody ICT services by integrating them in their lives.

These three essential criteria (as mentioned in the diagram) need to be fulfilled for motivating farmers to use telecentres' services. If one or more of the criteria are not met, farmers will not make use of telecentres. This is a dynamic model with a feedback loop that explicates continuous and iterative interactions among different components (farmers, technology and system).

Figure 3. A framework for user centric evaluation of telecentres

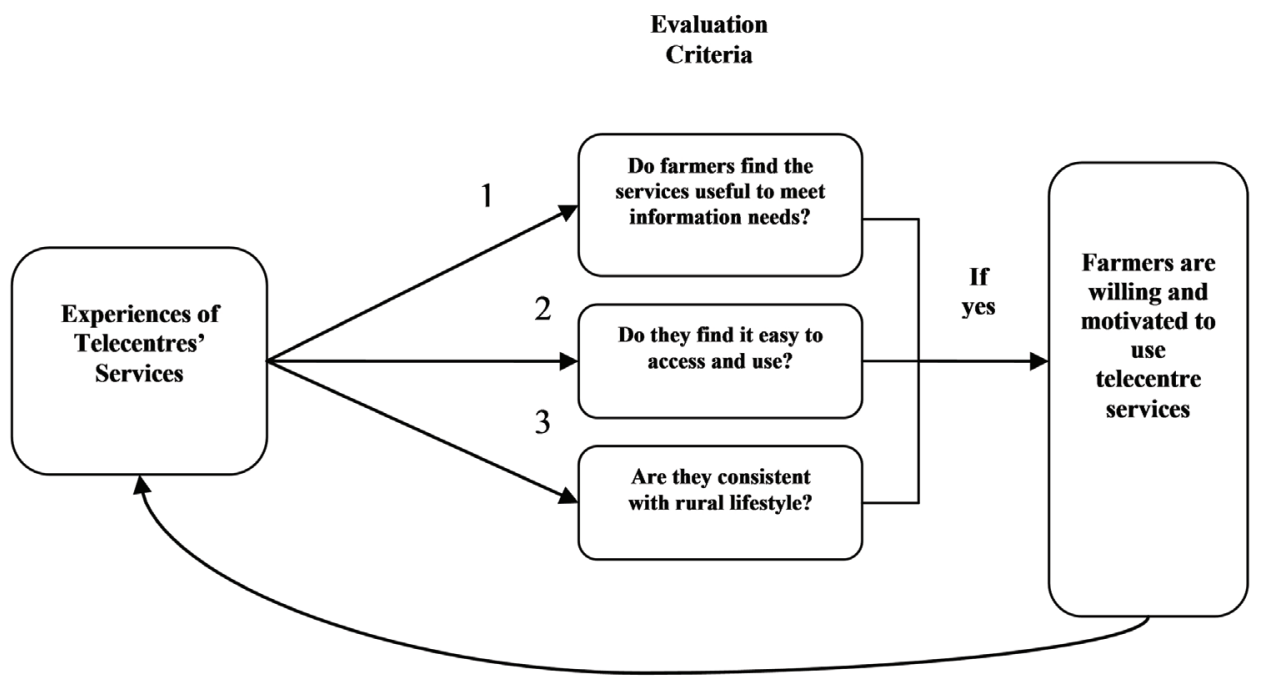

Farmers learn to use telecentres' services

1: Whether or not use of telecentres meets farmers' information needs?

2: Whether or not telecentres are easily accessible for farmers and how difficult are they to use?

3: Whether or not their services are embodied and appropriated? 
This paper narrates a useful methodology that not only creates opportunity for a particular target user group to access to the technology but also monitors the nature of the potential use and difficulties. In doing so, this paper argues that it is important to assess social and cultural contexts to identify the information needs of the targeted beneficiaries. Instead of top down assessment of ICT enabled projects, this paper explicates a bottom up approach to evaluation.

While econometric tools like TAM can hardly capture situational and contextual understanding, our model elicits how perceived usefulness and ease can be assessed through ethnographic observation to overcome this limitation. Qualitative techniques work better when dealing with beliefs and intentions, and changes over time (unlike snapshot questionnaires). When a technology is new to the intended users (e.g., mass use of mobile phones, a new telecentre), it is necessary to intervene, to make the technology accessible to a group of beneficiaries. There is no point asking questions about a technology only few people have previously used. That is why TAM questionnaires do not work in the early stages. Once the intervention has taken place, then we need to follow carefully how they appropriate the technologies into their lives. We have imported the basic constituents (perceived usefulness and perceived ease of use) of widely cited TAM model in the community informatics and tried to use them in developing a dynamic model with the help of structuration and appropriation concepts. Our future work will be aimed at constructing a comprehensive model involving an in-depth analysis of usability issues pertaining to farmers' adoption to ICT tools and applications.

\section{REFERENCES}

Bailey, A. (2009). Issues affecting the social sustainability of telecentres in developing contexts: a field study of sisteen telecentres in Jamaica. The Electronic Journal on Information Systems in Developing Countries, 36(4), 1-18.
Bailur, S. (2007). Using stakeholder theory to analyze telecentre projects. Information Technology and International Development, 3(3), 61-80. doi:10.1162/ itid.2007.3.3.61

Baron, S., Patterson, A., \& Harris, K. (2006). Beyond technology acceptance: understanding consumer practices. International Journal of Service Industry Management, 17(2), 111-135. doi:10.1108/09564230610656962

Bayes, A. (2001). Infrastructural and rural development: insights from a Grameen Bank village phone initiative in Bangladesh. Agricultural Economics, 25, 261-272. doi:10.1111/j.1574-0862.2001.tb00206.x

Crow, B. (1999). Why is agricultural growth uneven? Class and the agrarian surplus in Bangladesh. In Sonar Bangla? The Agricultural Growth and Agrarian Change in West Bengal and Bangladesh (pp. 147-171). Thousand Oaks, CA: Sage Publications.

Dao, M. K. (2004). Rural poverty in developing countries: an empirical analysis. Journal of Economic Studies (Glasgow, Scotland), 31(6), 500-508. doi:10.1108/01443580410569244

Davis, F. D. (1989). Perceived usefulness, perceived ease of use, and user acceptance of information technology. Management Information Systems Quarterly, 13(3), 319-340. doi:10.2307/249008

DeSanctis, G., \& Poole, M. S. (1994). Capturing the complexity in advanced technology Use: adaptive structuration theory. Organization Science, 5(2), 121-127. doi:10.1287/orsc.5.2.121

Donner, J. (2008). Research approaches to mobile use in the developing world: A review of literature. The Information Society: An International Journal, 24(3), 140-159.

Elliott, R., \& Jankel-Elliott, N. (2003). Using ethnography in strategic consumer research. Qualitative Market Research: An International Journal, 6(4), 215-223. doi:10.1108/13522750310495300

Giddens, A. (1982). Profiles and critiques in social theory. New York: The MacMillan Press Ltd.

Harris, R. (2001, November 29-30). Telecentres in rural Asia: towards a success model. In Proceedings of the International conference of on Information Technology, Communications and Development (ITCD 2001) (pp. 71-111). Retrieved October 20, 2008, from www.itcd.net 
Heeks, R. (1999). Information and communication technologies, poverty and development (Development Informatics Working Paper). Retrieved March 25, 2007, from http://www.sed.manchester.ac.uk/ idpm/research/publications/wp/di/di_wp05.htm

Kanungo, S. (2004). On the emancipatory role of rural information systems. Information Technology \& People, 17(4), 407-422. doi:10.1108/09593840410570267

Kiplang'at, J. (1999). An analysis of the opportunities for information technology in improving access, transfer and the use of agricultural information in the rural areas in Kenya. Library Management, 20(2), 115-127. doi:10.1108/01435129910251575

Kirlidog, M., \& Aydemir, A. T. (2005). Determinants of culture on a rural CI project. In Proceedings of the Community informatics research network 2005, PhD Colloquium and Conference (pp. 161-175).

Kizilaslan, N. (2006). Agricultural information systems: a national case study. Library Review, 55(8), 497-507. doi:10.1108/00242530610689347

Leaning, M. (2005). The modal nature of ICT: Challenging the historical interpretation of the social understanding and appropriation. In Proceedings of the Community informatics research network 2005, PhD Colloquium and Conference (pp. 311-319).

Lio, M., \& Liu, M. (2006). ICT and agricultural productivity: evidence from cross-country data. Agricultural Economics, 34, 221-228. doi:10.1111/ j.1574-0864.2006.00120.x

Millen, D. R. (2000). Rapid ethnography: time deepening strategies for HCI field research. In Proceedings of the 3rd Conference on Designing Interactive Systems: Processes, Practices, Methods and Techniques, New York (pp. 280-286).

Mutula, S. (2005). Bridging the digital divide through e-governance: A proposal for Africa's libraries and information centres. The Electronic Library, 23(5), 591-602. doi:10.1108/02640470510631308

Nikam, K., Ganesh, A. G., \& Tamizhchelevan, M. (2004). The changing face of India. Part I: bridging the digital divide. Library Review, 53(4), 213-219. doi:10.1108/00242530410531839

O'Brien, J., Rodden, T., Rouncefield, M., \& Hughes, J. (2000). At home with the technology: ethnographic study of a set-top-box trial. ACM Transactions on Computer-Human Interaction, 6(3), 282-308. doi:10.1145/329693.329698
Orlikowski, W. J. (1992). The duality of technology: rethinking the concept of technology in organizations. Organization Science, 3(3), 398-247. doi:10.1287/ orsc.3.3.398

Rogaly, B., Harris-White, B., \& Bose, S. (1999). Introduction: agricultural growth and agrarian change in West Bengal and Bangladesh. In Sonar Bangla? The Agricultural Growth and Agrarian Change in West Bengal and Bangladesh (pp. 11-40). Thousand Oaks, CA: Sage Publications.

Sey, A. (2008). Public access to ICTs: a review of the literature. Centre for Information and Society. Retrieved December 2, 2008, from http:/www.cis. washington.edu/wp-content/uploads/2008/10/ipailit-review-10-08.pdf

Snowden, S., Spafford, J., Michaelides, R., \& Hopkins, J. (2006). Technology acceptance and mcommerce in an operational environment. Journal of Enterprise Information Management, 19(5), 525-539. doi:10.1108/17410390610703657

Stillman, L., \& Stoecker, R. (2005). Structuration, ICT and community. The Journal of Community Informatics, 1(3), 83-102.

Talbot, C., \& Newman, D. R. (1998). Beyond Access and Awareness: Evaluating Electronic Community Networks. London: British Library. Retrieved September 25, 2008, from http://www.qub.ac.uk/mgt/ cicn/beyond/

Todaro, M. P. (2000). Economic Development (1st ed.). Reading, MA: Addison Wesley Longman Inc.

Ullah, A. K. M. A., \& Routray, J. K. (2007). Rural poverty alleviation through NGO interventions in Bangladesh: how far is the achievement? International Journal of Social Economics, 34(4), 237-248. doi:10.1108/03068290710734208

Venkatesh, A., Stolzoff, N., Shih, E., \& Mazumdar, S. (2001). The home of the future: an ethnographic study of new information technology in the home. Advances in Consumer Research. Association for Consumer Research (U. S.), 28, 88-96.

Venkatesh, V., \& Bala, H. (2008). Technology acceptance model 3 and a research agenda on intervention. Decision Sciences, 39(2), 273-315. doi:10.1111/j.1540-5915.2008.00192.x

Venkatesh, V., \& Davis, F. D. (2000). A theoretical extension of the technology acceptance model: four longitudinal field studies. Management Science, 46, 186-204. doi:10.1287/mnsc.46.2.186.11926 
Weilenmann, A. (2001). Negotiating use: making sense of mobile technology. Personal and Ubiquitous Computing, 5, 137-145. doi:10.1007/PL00000015

Whyte, A. (2000). Assessing community telecentres: a guideline for researchers. Ottowa, Canada: IDRC.

Wiredu, G. O. (2007). User appropriation of mobile technologies: Motives, conditions and design properties. Information and Organization, 17, 110-129. doi:10.1016/j.infoandorg.2007.03.002

\section{ENDNOTES}

www.dnet-bangladesh.org

www.katalystbd.com

http://www.transana.org/

All quotations have been recorded and translated from Bengali by the first author

TK stands for Taka, Bangladeshi currency. $1 \mathrm{US} \$=$ TK 68.80 (on $22^{\text {nd }}$ Sept 2009) a local unit of rice, equals to $37 \mathrm{~kg}$ approximately

Bidit Lal Dey is a final year Ph.D. student at the Queen's University Management School, Queen's University Belfast and also an Assistant Professor of American International University - Bangladesh (AIUB). His Ph.D. research investigates how mobile telephony can be used and appropriated by rural Bangladeshi farmers and what could be the potential nature and impact of such interaction. His research interest entails acceptance and appropriation of technology in developing societies. Mr. Dey's teaching interest centers on consumer behavior, services marketing and international marketing. He is also an Associate Editor of the International Journal of Innovation in the Digital Economy.

David Rudolf Newman is a lecturer at the Queen's University Management School. His research interest involves all interactions between technologies, people and the environment, including community informatics, e-governance, computer supported co-operative learning and appropriate IT for development. Dr. Newman has been involved in a number of research projects funded by EPSRC, European Commission, EU Peace II Programme and FP6. He has a Ph.D. in appropriate technology in the Third World and M.Sc. in artificial intelligence. He has worked in Mozambique and the Kenyatta University Appropriate Technology Centre in Kenya.

Renee Prendergast is a Reader in Economics at the Management School in Queen's University Belfast. Her research interests are in development economics and the history of economic thought. She is author leditor of Choice of Technique in Iron founding, 1984; The Machine Tool Industry in Developing countries, 1984; Development Perspectives for the 1990s, 1991; Market Forces and World Development, 1994; and Contributions to the History of Economic Thought, 2000. Recent work on the theory of development has included papers on the contributions of Marshall, Schumpeter and Commons and Sen. 